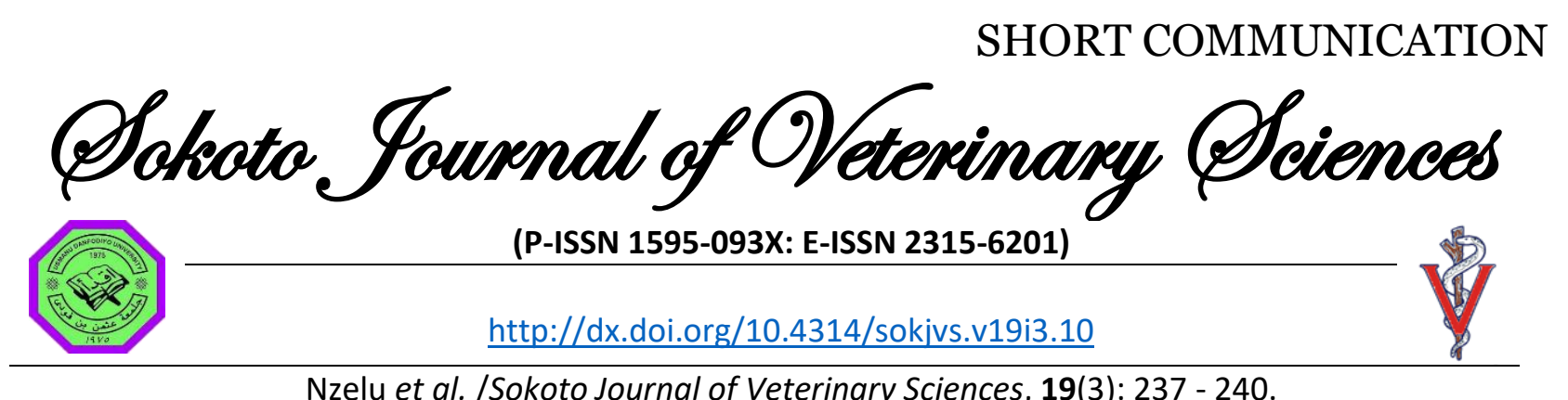

\title{
Seroprevalence of anti-toxoplasma gondii antibodies in free- range chickens in Kaduna metropolis, Nigeria
}

\author{
IN Nzelu ${ }^{1 *}$, BD Shingyu² \& JKP Kwaga ${ }^{2}$ \\ 1. Department of Veterinary Public Health and Preventive Medicine, College of Veterinary Medicine, Joseph \\ Sarwuan Tarka University Makurdi, Nigeria \\ 2. Department of Veterinary Public Health and Preventive Medicine, Faculty of Veterinary Medicine, Ahmadu \\ Bello University, Zaria, Nigeria
}

*Correspondence: Tel.: +2348037727690; E-mail: nancynzelu@gmail.com

\begin{abstract}
Copyright: (c) 2021 Nzelu et al. This is an open-access article published under the terms of the Creative Commons Attribution License which permits unrestricted use, distribution, and reproduction in any medium, provided the original author and source are credited.
\end{abstract}

Publication History: Received: 04-03-2021

Revised: 13-06-2021

Accepted: 22-06-2021

Keywords: Chickens, ELISA, Free-range, Kaduna, Nigeria, Toxoplasma gondii

\begin{abstract}
Free-range chickens play a vital role in the epidemiology of toxoplasmosis because they feed on the ground, exposing them to infective oocysts shed by cats that contaminate the environment. The role of chickens in the epidemiology of toxoplasmosis in Nigeria is understudied. Therefore, in the present study, we surveyed 222 free-range chickens slaughtered for human consumption in Kaduna metropolis, Nigeria, for the presence of anti- $T$. gondii antibodies using indirect enzyme-linked immunosorbent assay (iELISA). Of the total birds sampled, $27.9 \%$ (62/222) were seropositive. Results showed no statistically significant association between seroprevalence and sex $(p>0.05)$. The study has demonstrated the presence of anti- $T$. gondii antibodies in free-range chickens in Kaduna, Nigeria, indicative of exposure of the sampled chickens to T. gondii oocysts. Proper cooking of poultry meat obtained from the study location is advocated to avoid exposure to T. gondii.
\end{abstract}

\section{Introduction}

Toxoplasma gondii infection is distributed worldwide. People become infected by ingestion of infected undercooked or raw meat, accidental ingestion of infective oocysts from water or food, and contaminated soil (Dubey, 2010a). Human infection can also occur through blood transfusion, organ transplantation and transplacentally from an infected mother to the foetus (CDC, 2020). Felids are the definitive host of the causative agent, Toxoplasma gondii. They become infected by eating infected tissues from intermediate hosts and excrete environmentally resistant oocysts (Dubey, 2010b).

Free-range chickens play an essential role in the epidemiology of $T$. gondii infection. As they feed on the ground, they are considered one of the best indicators of soil contamination with $T$. gondii. They 
are important sources of infection for cats that shed infective oocysts that contaminate the environment (Dubey, 2010b). Toxoplasma gondii rarely causes clinical disease in chickens (Dubey, 2010b), but chickens can harbour mice-virulent $T$. gondii strains (Dubey et al., 2002).

The role of free-range chickens in the epidemiology of T. gondii infection in Nigeria has not been adequately investigated; only a few studies have been conducted thus far, with varying seroprevalence reported using various techniques (Aganga \& Belino, 1984; Ayinmode \& Dubey, 2012; Ayinmode \& Olaosebikan, 2014; Ayinmode \& Akinboboola, 2015; Aliyu et al., 2020).

On the other hand, there are several reports of human T. gondii infection in Nigeria, including Kaduna state (Bello et al., 2017; Lawal et al., 2018). Chickens being an indicator for establishing soil contamination with $T$. gondii oocyst and the absence of any published report about the infection in chickens in Kaduna state, the current study set out to assess the seroprevalence of anti- $T$. gondii antibodies in freerange chickens slaughtered at Sokoto Road live bird market in Kaduna city, Nigeria.

\section{Materials and Methods \\ Ethical approval}

The present study was a pilot study within a larger research project with approval obtained from Ahmadu Bello University Committee on Animal Use and Care (ABUCAUC), with approval number: ABUCAUC/2016/0017.

\section{Study area}

The study was conducted in Kaduna city, the capital of Kaduna State, located in the north-western region of Nigeria. The study location was the Sokoto Road live bird market within the city centre, with geographic coordinates of $10.53011,7.43481$. Sokoto road live bird market is one of the largest live bird markets in Kaduna city.

\section{Study design and sampling procedure}

From September to December 2016, a cross-sectional study approach was used to determine the seroprevalence of anti-Toxoplasma gondii antibodies in free-range chickens in the study area. On each sampling day at the market, birds to be sampled were selected by obtaining an equal number of birds from each recruited seller, and birds were selected by convenience from each batch of birds from each seller.

\section{Sample collection}

Blood samples were collected from 222 free-range chickens bought by customers at Sokoto Road live bird market in Kaduna and sent for slaughter at the market's slaughter slab. Samples were collected into blood collection tubes without EDTA, placed in a cold box and transported to the Veterinary Public Health and Preventive Medicine Laboratory, Ahmadu Bello University, Zaria, for processing. The sex of the birds was noted. Serum was extracted from blood samples by centrifugation at 5,000 rpm for 10 minutes and stored at $-20{ }^{\circ} \mathrm{C}$ until required for serology.

\section{Serology}

Sera samples were subjected to indirect ELISA using a commercial kit (ID Screen ${ }^{\circledR}$ Avian Toxoplasmosis Indirect, ID.vet, France) to detect anti-T. gondii antibodies. The assay was validated and carried out according to the manufacturer's instructions. Samples presenting an S/P ratio greater than $50 \%$ were considered positive.

\section{Statistical analysis}

Data were analysed using a statistical package for social science (SPSS) version 23.0 (SPSS Inc. Chicago, IL, USA). Statistical methods employed included descriptive statistics utilising frequencies and percentages. A Chi-square test was used to establish an association between the infection status of the sampled birds and sex. Statistical significance at a probability of $5 \%(P<0.05)$ with a confidence interval of $95 \%$ was adopted.

\section{Results and Discussion}

Of the total birds sampled, 27.9\% (62/222) were $T$. gondii seropositive. About equal seroprevalence was observed in male and female chickens at $27.9 \%$ and $28.0 \%$, respectively. Results showed no statistically significant association between seroprevalence and $\operatorname{sex}(p>0.05)($ Table 1$)$.

Table 1: Sex-specific seroprevalence of anti-Toxoplasma gondii antibodies in free-range chickens slaughtered for human consumption in Kaduna, Nigeria

\begin{tabular}{lllll}
\hline Sex & Total sampled & No. positive & Specific prevalence (\%) & ${ }^{*}$ v value \\
\hline Male & 129 & 36 & 27.9 & 0.993 \\
Female & 93 & 26 & 28.0 & \\
Total & 222 & 62 & 27.9 & \\
\hline
\end{tabular}

*Statistical method used: Chi-square test of association, $\mathrm{df}=1, \alpha=0.05$ 
The findings of the present study have demonstrated the presence of anti- $T$. gondii antibodies circulating in free-range chickens in the Kaduna metropolis, suggesting that the sampled birds were exposed to environments contaminated with $T$. gondii oocysts. This finding implies that meat from birds in the study area may contain cysts of $T$. gondii. This situation puts the health of those who work with slaughtered chickens in the study area at risk because they can become infected with $T$. gondii if proper hand hygiene is not practised.

This study's seroprevalence is low in comparison to previous studies (Ayinmode \& Dubey, 2012; Ayinmode \& Olaosebikan, 2014), but higher than reports by Ayinmode and Akinboboola (2015). These studies suggested that MAT is a more sensitive method for detecting anti-T. gondii antibodies than IFAT (Ayinmode and Akinboboola, 2015). In comparison to a previous study (Aliyu et al., 2020) that used iELISA, the current study had a higher seroprevalence. The differences in prevalence reported in the various studies may be due to the type of technique used. Anti-T. gondii antibodies in chickens can be detected using a variety of serological assays, each with its own cut-off titre for determining clinically significant levels of anti-Toxoplasma antibodies. Variation among different serological tests was reported in a study in Brazil (Casartelli-Alves et al., 2014) where different seroprevalence was obtained for different methods using the same samples. Studies have shown that ELISAs are generally suitable for the detection of anti-T. gondii antibodies in domestic and wild animals (Gamble et al., 2005; Gamble et al., 2019) and having comparable detection levels with MAT (Gamble et al., 2019). The ELISA kit used in the present study is a validated test kit manufactured for use in birds. Variations in seroprevalence could also be due to differences in study location, as the previous studies were conducted primarily in the southwestern region of the country, whereas the current study was done in northwest Nigeria.

When compared to surveys conducted outside of Nigeria that used ELISA as the diagnostic method, the current study had a lower prevalence than Barakat et al. (2012) but a higher prevalence than Ding et al. (2012). This suggests that $T$. gondii seroprevalence varies by continent. The current study found that sex is not a determinant in $T$. gondii infection in freerange chickens. This indicates that both male and female chickens are equally susceptible to $T$. gondii infection. This finding is consistent with Ayinmode and Akinboboola (2015) and Grebremedhin et al. (2015).
In conclusion, the study has demonstrated that anti$T$. gondii antibodies are circulating in free-range chickens in Kaduna, indicative of exposure of the birds to an environment contaminated with $T$. gondii oocysts. Because free-range chickens are important sentinels in the parasite's epidemiology and potential sources of human infection, it is critical that high-risk individuals in the state take adequate precautionary measures to avoid infection, as toxoplasmosis can be fatal in immunocompromised patients. To avoid infection, the authors recommend that meat from free-range chickens in the study area be properly cooked or frozen overnight before consumption and that meat handlers properly wash their hands after handling meat to avoid the risk of infection with $T$. gondii.

\section{Acknowledgement}

The authors appreciate ID.vet France for providing ELISA kits used in the study free of charge.

\section{Conflict of Interest}

The authors declare that there is no conflict of interest.

\section{References}

Aganga AO \& Belino ED (1984). Toxoplasmosis in local breed of chicken in Zaria, Nigeria. International Journal of Zoonoses, 11(2): 170172.

Aliyu MB, Maikai BV \& Magaji AA (2020). Toxoplasma gondii infection and risk factors associated with its spread at live bird markets in Katsina Metropolis, Nigeria. Sokoto Journal of Veterinary Sciences, 18(1): 39-46.

Ayinmode AB \& Akinbobola RJ (2015). Detection of Toxoplasma gondii IgG antibodies in Nigerian free-range chickens using indirect fluorescent antibody test (IFAT). Alexandria Journal of Veterinary Sciences, 47(1): 187-190.

Ayinmode AB \& Dubey JP (2012). Toxoplasma gondii infection in free-range chicken: mini-review and seroprevalence study in Oyo state, Nigeria. African Journal of Biomedical Research, 15(3): 145-148.

Ayinmode AB \& Olaosebikan RIA (2014). Seroprevalence of Toxoplasma gondii in freeranged chickens from rural and urban settlements in Oyo state, Nigeria. African Journal of Medicine and Medical Sciences, 43: 51-57.

Barakat AM, Salem LM, El-Newishy AM, Shaapan RM \& El-Mahllawy EK (2012). Zoonotic chicken toxoplasmosis in some Egyptians 
Governorates. Pakistan Journal of Biological Sciences, 15(17): 821-826.

Bello HS, Umar YA, Abdulsalami MS \& Amusan VO (2017). Seroprevalence and Risk Factors of Toxoplasmosis among Pregnant Women Attending Antenatal Clinic in Kaduna Metropolis and Environs. International Journal of Tropical Disease and Health, 23(3): 1-11.

Casartelli-Alves L, Boechat VC, Macedo-Couto R, Ferreira LC, Nicolau JL, Neves LB, Millar PR, Vicente RT, Oliveira RVC, Muniz AG, Bonna ICF, Amendoeira MRR, Silva RC, Langoni $H$, Schubach TMP \& Menezes RC (2014). Sensitivity and specificity of serological tests, histopathology and imunohistochemistry for detection of Toxoplasma gondii infection in domestic chickens. Veterinary Parasitology, 204(3-4): 346-351.

Center for Disease Control and Prevention (CDC) (2020). Toxoplasmosis (Toxoplasma infection): biology.

https://www.cdc.gov/parasites/toxoplasmosi s/biology.html, retrieved on 15-02-2020.

Ding GE, Xu MB, Zhou YH, Fang F \& Cui HP (2012). Sero-epidemiological survey of chickens infected with Toxoplasma gondii in Wuxi city. Chinese Journal of Schistosomiasis Control, 24(2): 243-245.

Dubey JP (2010a). Toxoplasmosis of Animals and Humans. Second edition. CRC Press, Boca Raton, Florida. Pp 1-313.

Dubey JP (2010b). Toxoplasma gondii infections in chickens (Gallus domesticus): prevalence, clinical disease, diagnosis and public health significance. Zoonoses and Public Health, 57(1): 60-73.

Dubey JP, Graham DH, Blackston CR, Lehmann T, Gennari SM, Ragozo AMA, Nishi SM, Shen SK, Kwok OCH, Hill DE \& Thulliez P (2002). Biological and genetic characterisation of Toxoplasma gondii isolates from chickens (Gallus domesticus) from Sao Paulo, Brazil: unexpected findings. International Journal for Parasitology, 32(1): 99-105.

Gamble A, Ramosb R, Parra-Torresb Y, Mercierc A, Galal L, Pearce-Duveta J, Villenae I, Montalvog T, González-Solísb J, Hammoudai A, Oroj D, Selmii S \& Bouliniera T (2019). Exposure of yellow-legged gulls to Toxoplasma gondii along the Western Mediterranean coasts: Tales from a sentinel. International Journal for Parasitology: Parasites and Wildlife, doi: 10.1016/j.ijppaw.2019.01.002.

Gamble HR, Dubey JP \& Lambillotte DN (2005). Comparison of a commercial ELISA with the modified agglutination test for detection of Toxoplasma infection in the domestic pig. Veterinary Parasitology, 128(3-4): 177-181.

Grebremedhin EZ, Tesfamaryam G, Yunus HA, Duguma R, Tilahun G, Di Marco V \& Vitale $M$ (2015). Seroepidemiology of Toxoplasma gondii infection in free-range chickens (Gallus domesticus) of Central Ethiopia. Epidemiology and Infection, 143(3): 608-617.

Lawal SM, Inabo HI \& Ella EE (2018). Seroprevalence of Toxoplasma gondii Antibodies and Associated Risk Factors among School Children in Parts of Kaduna State, Nigeria. Journal of Advances in Microbiology, 10(1): 1-10. 